\title{
Are Medical Students willing to Patronize Traditional Bone Setters in the Future? A Study among Medical Students of Ebonyi State University Abakaliki, Nigeria
}

Ossai EN ${ }^{1,2}$, Agu CI'2, Eze II',2, Alo AT

${ }_{1}^{1}$ Department of Community Medicine, College of Health Scences, Ebonyi State University Abakaliki, Nigeria 2Department of Community Medicine, Alex Ekwueme Federal University Teaching Hospital Abakaliki, Nigeria

Keywords
Medical
students;
Traditional
Bonesetters;
Willingness;
Abakaliki;
Nigeria.

\section{ABSTRACT}

Background: A large proportion of fractures are still managed by traditional bone setters in developing nations. The study was designed to determine the willingness to patronize traditional bone setters in the future among medical students of Ebonyi State University Abakaliki, Nigeria.

Methods: This was a descriptive cross-sectional study of all preclinical and clinical medical students of the university. Information was obtained using a pretested, selfadministered questionnaire. Data were analyzed using IBM SPSS statistical software version 22.0 and level of statistical significance was determined by a p value of $<0.05$.

Results: A total of 385 students participated in the study (response rate; $83.7 \%$ ). Mean age of respondents was $23.2 \pm 3.4$ years. One quarter of the respondents, $82(25.0 \%)$ have patronized traditional bone setters before. About half indicated that traditional bone setters receive more patronage than orthopedic surgeons, however three-quarters of them preferred services of Surgeons. Two-thirds opined that bone setters have more treatment failures, and only $72(18.7 \%)$ were willing to patronize traditional bone setters in future. Major reasons to patronize them included skilled/good service delivery, 34 $(47.2 \%)$ and low cost, $21(29.2 \%)$. Predictor of willingness to patronize traditional bone setters in future was previous use of traditional bone setters, (AOR=8.3, 95\% CI: 4.7-14.9, $\mathrm{p}<0.001)$

Conclusion: The practice of traditional bone setting is widespread and enjoys much acceptance in the society despite high rates of treatment failures associated with it. Thus, there is the need to monitor the activities of traditional bone setters to enhance competence and encourage referral.

\author{
Correspondence to: \\ Chibuike Innocent Agu \\ aguchibuike14@yahoo.com \\ Phone number: 08036957505
}

\section{INTRODUCTION}

In many developing nations, a considerable proportion of fractures are being managed by traditional bone setters (TBS) who are easily available and accessible. ${ }^{1}$ Traditional bone setting is an aspect of traditional medical approach concerned with the management of fractures, dislocations, congenital anomalies, ligament sprain, spine sprain and mobile muscular pains. ${ }^{2}$ It has been in existence on a global scale for a 
long time, with evidence showing that it has coexisted with orthodox care in China for decades. ${ }^{3,4}$ In many parts of the developing world, where they still play a major role in the primary care of bone injuries, traditional bonesetters have practised long before the advent of orthopaedics. ${ }^{5}$ They constitute an integral part of trauma care in Nigeria, providing up to $70 \%-90 \%$ of primary fracture care in some areas. 6,7

Traditional bonesetters still enjoy patronage from the rich, the poor, uneducated and highly educated members of the Nigerian society. ${ }^{8}$ Their clients range from the newborn with musculoskeletal deformity to the very old with fractures. ${ }^{9-11}$ Reasons for such high patronage are varied and include, but not restricted to low cost, easy accessibility, fear of amputation at the hospital, dissatisfaction with hospital treatment and trust in the competence of traditional bonesetters. ${ }^{9,12}$ In addition, poverty, ignorance, culture and superstition have been cited as factors influencing the continued use of native bone setting. 12,13 Although traditional bonesetters record some success in the management of simple fractures and dislocations, their activities hamper the smooth practice of modern orthopaedics and traumatology in our society. The practice contributes significantly to complications and poor outcomes of orthopaedic conditions, and constitute enormous challenges to the practitioners of orthopaedics in Nigeria and other African countries. ${ }^{14}$ Available evidence shows that they employ the use of concoctions, unsanitary and tight splint on fractures, which often result in compartment syndrome, and then, gangrene. ${ }^{15-17}$ It, therefore, comes as no surprise that approximately, $60 \%$ of major limb amputations and as much as $80 \%$ of fracture morbidity in hospitals in Nigeria are attributed to their actions. ${ }^{5}$

Moreover, the process of training and skills acquisition in traditional bone setting is flawed. It is neither formal nor structured, and there is no training in basic medical sciences.7,18 In fact, educational qualification is not considered relevant for the art as only apprenticeship is enough for recruitment into the practice. ${ }^{19}$ Their services are well-kept family secrets and ancestral heritage, handed down the generations through oral tradition. 5,11,15,20 The activities are, also, undocumented, shrouded in mystery, culture, fetish practices and incantations. ${ }^{16,17}$ They are not regulated, and thus, quality may be questionable. ${ }^{19-21}$ In addition to the aforementioned, they hardly refer cases beyond them to hospitals. ${ }^{11,22}$

Notwithstanding the shortcomings, there is still a high rate of acceptance and patronage among the populace. The demand is such that some patients on admission abandon hospitals to seek treatment from traditional bonesetters. 23,24 The hospital for the clinical training of the medical students is one of the major teaching hospitals in Southeast, Nigeria and it has capacity to provide care for fracture and other forms of trauma. ${ }^{25}$ However, a study which assessed the early outcome of road traffic injuries in the 
institution's emergency room reported that some of the patients left the hospital, even against medical advice, for traditional bone setters, citing their supernatural powers to treat bone injuries as reasons for opting for them. ${ }^{26}$ About $78 \%$ of such self-discharge against medical advice were cases of either fracture or dislocation.

In the light of this and the extensive nature of the traditional bone setting in Ebonyi State and other Nigerian states, ${ }^{7}$ this study was designed among medical students of Ebonyi State University Abakaliki, Nigeria to assess their willingness to patronize traditional bonesetters. This will help generate information which will be useful in tackling some of the culturally rooted misconceptions about the practice of traditional bone setting. In addition, their knowledge and status as medical students puts them in a good position to create awareness about proper fracture management, and to help disabuse the minds of the populace regarding some wrong views held about the practice of orthopaedics in hospitals.

\section{METHODOLOGY}

\section{Study setting}

The study was conducted in the medical school of Ebonyi State University, both of which are located in Abakaliki, the capital city of Ebonyi State, South-east Nigeria. The medical school was established in 1999, the same year the university came into existence. In Nigeria, the training of medical doctors is for a period of six years. The first year is called the preliminary year while the second and third years are pre-clinical years. The clinical period of medical training involves the fourth to the sixth year of training. The university admits an average of one hundred students each year. As at the time of the study, 460 students were in the pre-clinical and clinical period of training in the medical school.

Health services in Ebonyi state are provided through two tertiary and thirteen secondary hospitals, four hundred and seventeen primary health centers, six faith-based hospitals and numerous private hospitals/clinics. ${ }^{27}$ The tertiary hospitals are situated in the capital city, while one secondary facility is in each local government area of the state

\section{Study design and study population}

This was a descriptive cross-sectional study carried out in October, 2019. The study population were preclinical and clinical medical students of Ebonyi State University Abakaliki, Nigeria.

\section{Sample size determination}

This was a total population study of all preclinical and clinical medical students of Ebonyi State University Abakaliki, Nigeria. This includes students from second year to final year of study. As at the time of the study, a total of 460 students were in the pre-clinical and clinical period of training. Three hundred and eighty-five students participated in the study representing a response rate of $83.7 \%$. 


\section{Study instrument}

A structured questionnaire pre-tested among medical students of University of Nigeria, Enugu campus, (UNEC), Enugu State was used for data collection. The questionnaire which was designed by the researchers was self-administered.

\section{Data management}

Data collection and editing was done manually to detect omission and ensure uniform coding. Data entry and analysis were done using IBM Statistical Package for Social Sciences (SPSS) version 22.0. Frequency tables and cross-tabulations were generated. Chi-square test and multivariate analysis using binary logistic regression analysis were done. The level of statistical significance was set at $\mathrm{p}<0.05$. The outcome measure of the study was the proportion of respondents that were willing to patronize traditional bonesetters in future. In determining the factors that were associated with willingness of respondents to patronize traditional bone setters in future, variables having $p$-value of $\leq 0.2$ in bivariate analysis were entered into the logistic regression model to determine the predictors of willingness to patronize the traditional bonesetters in future. Result of the binary logistic regression analysis was presented using adjusted odds ratio and 95\% confidence interval and level of statistical significance was determined by a p-value of $<0.05$.

\section{Ethical approval}

The Research and Ethics Committee of Ebonyi State University Abakaliki, Nigeria gave ethical approval, with reference number, EBSU/DRIC/UREC/Vol. 04/064, for the study. The students signed a written informed consent form before participating in the study. Participation in the study was voluntary and participants were assured that there would be no victimization of anyone who did not want to participate or those who decided to withdraw after giving consent.

\section{RESULTS}

Table 1 shows the socio-demographic characteristics of the respondents. The mean age of the students was 23.2 \pm 3.4 years and the majority of the students were in the age group 20-24 years. Majority of the students, 247 (64.2\%) were males and 369 (95.8\%) were not married. The highest proportion of the respondents, 86 (22.3\%) were second-year students while the least proportion, $62(16.1 \%)$ were final year students.

Table 2 shows the awareness and willingness to patronize traditional bone setters in future. Majority of the respondents, 328 (85.2\%) were aware of traditional bone setting. A minor proportion, $82(25.0 \%)$ have patronized traditional bone setters before. Similarly, a minor proportion, $72(18.7 \%)$ were willing to patronize traditional bone setters in future.

Majority of the respondents, 200 (51.9\%) were of the opinion that traditional bone setters enjoy more patronage among the 
Table 1: Socio-demographic characteristics of respondents

\begin{tabular}{|c|c|c|}
\hline Variable & $\begin{array}{l}\text { Frequency } \\
(\mathrm{n}=385)\end{array}$ & Percent \\
\hline \multicolumn{3}{|l|}{ Age group (years) } \\
\hline$<20<<10-1$ & 49 & 12.5 \\
\hline $20-24$ & 222 & 57.7 \\
\hline$\geq 25$ & 114 & 29.6 \\
\hline \multicolumn{3}{|l|}{ Academic level } \\
\hline 200 level & 86 & 22.3 \\
\hline 300 level & 79 & 20.5 \\
\hline 400 level & 79 & 20.5 \\
\hline 500 level & 79 & 20.5 \\
\hline 600 level & 62 & 16.1 \\
\hline \multicolumn{3}{|l|}{ Sex } \\
\hline Male & 247 & 64.2 \\
\hline Female & 138 & 35.8 \\
\hline \multicolumn{3}{|l|}{ Ethnic group } \\
\hline Igbo & 371 & 96.4 \\
\hline Yoruba & 4 & 1.0 \\
\hline Minority ethnic groups & 10 & 2.6 \\
\hline \multicolumn{3}{|l|}{ Marital status } \\
\hline Single & 369 & 95.8 \\
\hline Married & 16 & 4.2 \\
\hline \multicolumn{3}{|l|}{ Religion } \\
\hline Christianity & 378 & 98.2 \\
\hline Islam & 4 & 1.0 \\
\hline Traditional religion & 3 & 0.8 \\
\hline \multicolumn{3}{|c|}{ Educational attainment of Father } \\
\hline No formal education & 25 & 6.5 \\
\hline Primary education & 39 & 10.1 \\
\hline Secondary education & 55 & 14.3 \\
\hline Tertiary education & 266 & 69.1 \\
\hline \multicolumn{3}{|c|}{ Educational attainment of Mother } \\
\hline No formal education & 30 & 7.8 \\
\hline Primary education & 48 & 12.5 \\
\hline Secondary education & 54 & 14.0 \\
\hline Tertiary education & 253 & 65.7 \\
\hline
\end{tabular}

Mean age of respondents $\pm(S D)=23.2 \pm 3.4$

people. Majority of the respondents, 289 $(75.1 \%)$ prefer the treatment from orthopedic surgeons to that of traditional bone setters. Figure 1 shows the reasons why people patronize traditional bone setters. The major reasons by the respondents why people patronize traditional bone setters included low cost/easy accessibility, 180 (46.8\%) and ignorance, 73 (19.0\%).

Table 3 shows factors associated with willingness to patronize traditional bone setters in future. A significantly higher proportion of respondents who were in preclinical school (23.6\%) were willing to patronize traditional bone setters in the future when compared with those in 
Table 2: Respondents' awareness and willingness to patronize traditional bonesetters in future

\begin{tabular}{|c|c|c|}
\hline Variable & Frequency & Percent \\
\hline \multicolumn{3}{|l|}{ Aware of traditional bone setting $(n=385)$} \\
\hline Yes & 328 & 85.2 \\
\hline No & 57 & 14.8 \\
\hline & & Fro \\
\hline $\begin{array}{l}\text { Have patronized traditional bone setters before } \\
(n=328)\end{array}$ & & \\
\hline Yes & 82 & 25.0 \\
\hline No & 246 & 75.0 \\
\hline \multicolumn{3}{|l|}{$\begin{array}{l}\text { Will patronize traditional bone setters in future } \\
(\mathrm{n}=385)\end{array}$} \\
\hline Yes & 72 & 18.7 \\
\hline No & 213 & 55.3 \\
\hline Not certain & 100 & 26.0 \\
\hline \multicolumn{3}{|l|}{$\begin{array}{l}\text { Reason to patronize traditional bone setters in future } \\
(n=72)\end{array}$} \\
\hline Skilled/good service delivery & 34 & 47.2 \\
\hline Low cost & 21 & 29.2 \\
\hline Reduced risk of amputation & 10 & 13.9 \\
\hline No specific reason & 7 & 9.7 \\
\hline \multicolumn{3}{|l|}{$\begin{array}{l}\text { Will encourage family members to patronize } \\
\text { traditional bone setters }\end{array}$} \\
\hline Yes $(\mathbf{n}=\mathbf{3 8 5})$ & 55 & 16.9 \\
\hline No & 240 & 62.3 \\
\hline Not certain & 80 & 20.8 \\
\hline \multicolumn{3}{|l|}{ More patronized by the people } \\
\hline Traditional bonesetters & 200 & 51.9 \\
\hline Orthopedic Surgeons & 91 & 23.6 \\
\hline Uncertain & 94 & 24.4 \\
\hline \multicolumn{3}{|l|}{ Respondents' preferred group for treatment $(n=385)$} \\
\hline Orthopedic Surgeons & 289 & 75.1 \\
\hline Traditional bonesetters & 42 & 10.9 \\
\hline Uncertain & 54 & 14.1 \\
\hline
\end{tabular}

clinical school $(15.0 \%)\left(x^{2}=4.625, p=0.032\right)$. A higher proportion of respondents who have patronized traditional boners setters before $(50 \%)$ were willing to patronize them in future when compared with those who have not patronized them before $(10.2 \%)$ and the difference in proportions was found to be statistically significant. $\left(x^{2}=63.132\right.$, $\mathrm{p}<0.001)$

Table 4 shows the predictors of willingness to patronize traditional bone setters in future. The respondents who have patronized traditional bone setters before were eight times more likely to patronize traditional bone setters in future when compared with those who have not patronized them before. (AOR=8.337, 95\%CI: 4.675-14.869, $\mathrm{p}<0.001)$.

\section{DISCUSSION}

In Nigeria, traditional bone setting provides as much as $70 \%-90 \%$ of primary fracture care in some areas.6,7 Thus, it is not surprising that majority of the respondents, 


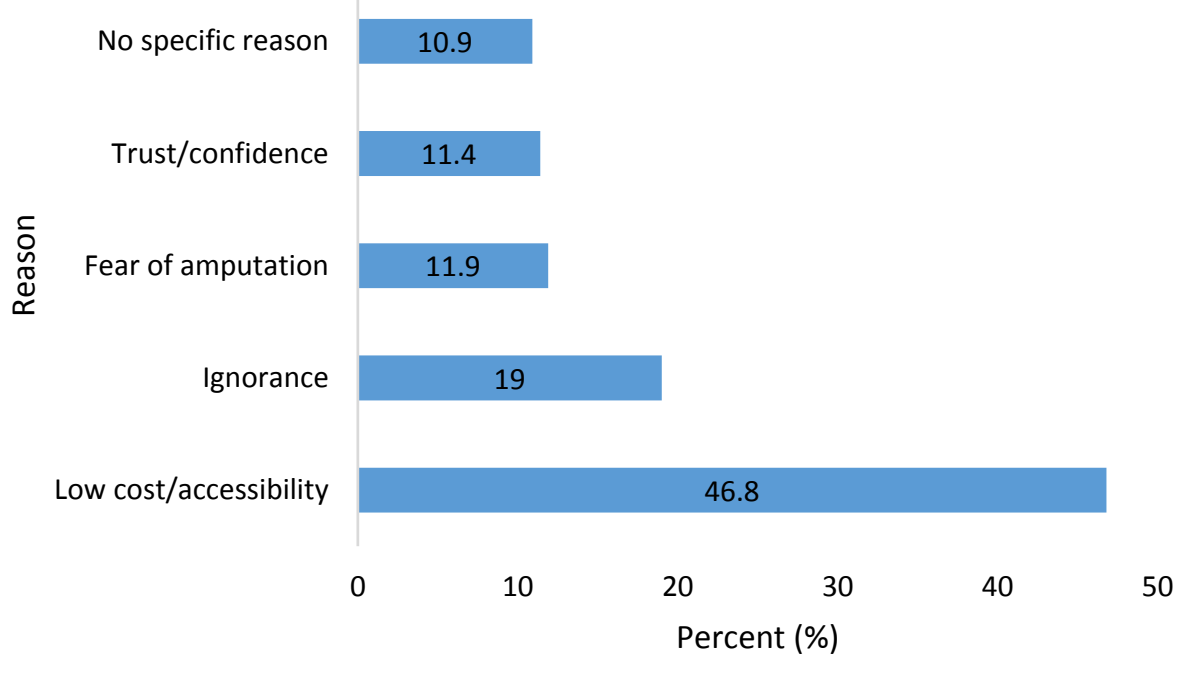

Figure 1: Reasons people patronize traditional bone setters

Table 3: Factors affecting willingness to patronize traditional bone setters in future

\begin{tabular}{|c|c|c|c|c|}
\hline Variable & $\begin{array}{l}\text { Willing to } p \\
\text { in future } \\
\text { Yes }(n=72) \\
n(\%)\end{array}$ & $\begin{array}{l}\text { ronize TBS } \\
\text { No }(n=313) \\
n(\%)\end{array}$ & $\mathbf{x}^{2}$ & p value \\
\hline \multicolumn{5}{|l|}{ Age group (years) } \\
\hline$<20$ & 7 (14.3) & $42(85.7)$ & 0.798 & 0.671 \\
\hline $20-24$ & $42(18.9)$ & $180(81.1)$ & & \\
\hline$\geq 25$ & $23(20.2)$ & $91(79.8)$ & & \\
\hline \multicolumn{5}{|l|}{ Sex } \\
\hline Male & $48(19.4)$ & 199 (80.6) & 0.243 & 0.622 \\
\hline Female & $24(17.4)$ & 114 (82.6) & & \\
\hline \multicolumn{5}{|l|}{ Marital status } \\
\hline Single & $70(19.0)$ & 299 (81.0) & 0.422 & 0.516 \\
\hline Married & $2(12.5)$ & $14(87.5)$ & & \\
\hline \multicolumn{5}{|l|}{ Period of training } \\
\hline Pre-clinical & 39 (23.6) & $126(76.4)$ & 4.625 & 0.032 \\
\hline Clinical & $33(15.0)$ & 187 (85.0) & & \\
\hline \multicolumn{5}{|c|}{ Patronized traditional bone setters before } \\
\hline Yes & $41(50.0)$ & $41(50.0)$ & 67.132 & $<0.001$ \\
\hline No & $31(10.2)$ & $272(89.8)$ & & \\
\hline \multicolumn{5}{|l|}{ Fathers educational attainment } \\
\hline Tertiary education & $47(17.7)$ & $219(82.3)$ & 0.603 & 0.437 \\
\hline Secondary education and less & $25(21.0)$ & $94(79.0)$ & & \\
\hline \multicolumn{5}{|c|}{ Mothers educational attainment } \\
\hline Tertiary education & $42(16.6)$ & $21183.4)$ & 2.141 & 0.143 \\
\hline Secondary education and less & $30(22.7)$ & $102(77.3)$ & & \\
\hline \multicolumn{5}{|c|}{ Place of family residence of students } \\
\hline Urban & $53(18.1)$ & $240(81.9)$ & 0.303 & 0.582 \\
\hline Rural & $19(20.7)$ & $73(79.3)$ & & \\
\hline
\end{tabular}

TBS - Traditional bone setters 
Table 4: Predictors of willingness to patronize traditional bone setters in future

\begin{tabular}{|c|c|c|c|c|}
\hline \multirow[t]{2}{*}{ Variable } & \multirow{2}{*}{$\begin{array}{l}\text { Adjusted Odds } \\
\text { ratio }\end{array}$} & \multirow{2}{*}{$\begin{array}{l}95 \% \text { Confidence } \\
\text { for Odds ratio } \\
\text { Lower }\end{array}$} & \multirow{2}{*}{$\begin{array}{l}\text { Interval } \\
\text { Upper }\end{array}$} & \multirow[t]{2}{*}{ p value } \\
\hline & & & & \\
\hline \multicolumn{5}{|l|}{ Period of training } \\
\hline Pre-clinical & 1.591 & 0.901 & 2.808 & 0.109 \\
\hline Clinical & 1 & & & \\
\hline $\begin{array}{l}\text { Mothers educational } \\
\text { attainment }\end{array}$ & & & & \\
\hline Tertiary education & 0.853 & 0.474 & 1.535 & 0.595 \\
\hline $\begin{array}{l}\text { Secondary education and } \\
\text { less }\end{array}$ & 1 & & & \\
\hline \multicolumn{5}{|l|}{$\begin{array}{l}\text { Patronized traditional } \\
\text { bone setters before }\end{array}$} \\
\hline Yes & 8.337 & 4.675 & 14.869 & $<0.001$ \\
\hline No & 1 & & & \\
\hline
\end{tabular}

$85.2 \%$ in this study were aware of the practice of traditional bone setting. This is consistent with the findings from studies in Kenya, south west and north-central parts of Nigeria in which 95\%, 88.1\%, and $77.3 \%$ of respondents respectively, were aware of the practice of bone setting. ${ }^{28-30}$ It also affirms the result of a related study in the study area, Abakaliki Ebonyi State, Nigeria, where $84.5 \%$ of the respondents were aware of traditional bone setters and their practices. ${ }^{12}$ The finding strengthens the notion that the practice is common and extensive in Nigeria. ${ }^{11}$ However, this level of awareness may be partly attributed to the aggressive programmes and advertisements in mass media usually undertaken by traditional bone setters and other traditional healers in order to boast their trade. 29

Similar to the observation that few patients had patronized traditional bone setters by a previous research in Abakaliki, Ebonyi
State, ${ }^{12}$ only few (25\%) of the respondents in our study had been to traditional bone setters for treatment of a health problem. A study in Ilorin South west, Nigeria, also, reported similar finding. ${ }^{31}$ However, another study in Ilorin documented that more than half of their respondents indicated having patronized a traditional bone setter. ${ }^{30}$ The second study in Ilorin was communitybased unlike the current one which was carried out in an institution, and this could be the reason for the difference in findings. Elsewhere in Ilesa, southwest Nigeria, it was recorded that about two-thirds of study respondents in a research went to a traditional bone setter from the sites of injury. ${ }^{32}$ The high figure in that study may be explained by the fact that it was a prospective study carried out among orthopedic patients in a hospital.

In the Nigerian society, the traditional bone setters perhaps more than any other group of traditional care-givers enjoy high 
patronage and confidence. ${ }^{8,11}$ This might be the explanation for about half of the respondents in our study to believe that traditional bone setters have more patronage than orthopedic surgeons. This further reinforces the belief that the practice of traditional bone setting is pervasive in our communities and hence constitutes an important part of health system in many developing countries. The practice has flourished as an alternative source of care, especially in rural communities, where the practitioners command a lot of respect and acceptance. 19,33 This may account for most patients with fracture presenting to the bone setters first before going to the hospital, perhaps, with complications. ${ }^{32}$

It comes as no surprise, however, that three quarters of the respondents in the present study would prefer treatment from orthopedic surgeons to that from traditional bone setters, considering that the study was among medical students who may have reservations about the activities of traditional bone setters, based on their knowledge of fracture management and the complications that could arise from fracture mismanagement. The result is in keeping with those from some previous facilitybased studies, ${ }^{12,34}$ but different from the findings from community-based ones, where majority of respondents preferred the services of traditional bone setters in lieu of orthopaedic surgeons. ${ }^{28,35}$ That a higher proportion of respondents believed that traditional bone setters had more treatment failures when compared with orthopaedic surgeons is in tandem with evidence from studies done in the past.7,12,36 These complications and bone setting failures arising from the practice of traditional bone setting have been described as a major contributor to the challenges facing the orthodox practice, and the literature is replete with reports of such failures.7,14,16 Studies in Turkey and India also indicated high rates of complications due to the activities of traditional bone setters. ${ }^{22,37}$ The high rate of failure has been linked to the methods used by traditional bone setters which are not based on scientific knowledge and basic principles of infection prevention and control.5,6,18,22,30 To this end, there have been calls to educate and train the traditional bone setters in effective management of open and closed fractures. ${ }^{6,22}$

Although patronage of the TBS is influenced by quite a number of factors, the major reasons given were low cost/accessibility, and ignorance. These are consistent with findings from studies done in Bangalore, 38 North-central 7 and South-eastern ${ }^{12}$ regions of Nigeria. It further, affirms the position by some authors that poverty is crucial to patronizing traditional bone setters. ${ }^{9}$ Fear of amputation was given by some respondents and this has also been documented by some studies as a major reason people go to traditional bone setters. ${ }^{13,30}$ Likewise, that up to $11.4 \%$ of the respondents held trust/confidence as a reason supports the opinion that people believe in the competence of traditional bone setters and hence, patronize them. ${ }^{8-10}$ 
As may be anticipated, a minor proportion of the respondents were willing to patronize traditional bone setters in the future. Similar results were documented in studies among health workers in Owo, Osun State, Nigeria. ${ }^{29}$ This may not be unconnected with the level of education as well as the course of training of the respondents in these studies. A study among a patient group in Abakaliki, Nigeria indicated that higher proportion of respondents would be willing to patronize traditional bone setter. ${ }^{12}$ In the current study, the major reason for willingness is skills / good service delivery, followed by low cost. This is similar to the ones given in the study in Abakaliki and another in Calabar where more than half of the patients had patronized traditional bone setters because they believed they were more competent than orthopaedic surgeons. ${ }^{12,39}$

That skills/good service delivery was cited as a reason by some respondents for possible future visitation to traditional bone setters is worrisome considering that these are medical students who should be in the forefront in the effort to correct the culturally rooted misconceptions about the skill and supernatural powers of traditional bone setters. Indeed, this is a reflection of the level of confidence in the competence of traditional bone setters in managing fractures among the general population. Sadly, low cost was one of the major reasons given by the respondents for future patronage of traditional bone setters. This is understandable as they are students who are unemployed and under financial control of their sponsors. It buttresses the report that occupation and income play important role in the decision to patronize traditional bone setters. ${ }^{14,30}$

The role of family members in the utilization of traditional orthopaedic services is highlighted in this study as few respondents were willing to encourage family members to patronize traditional bone setters should there be a need for fracture management in future. In this regard, studies done in Kwara State, Nigeria, and Pakistan reported that high proportions of patients were referred to traditional bone setters by immediate family members. 40,41

Interestingly, the respondents who had patronized traditional bone setters in the past, were eight times more likely to patronize them in future when compared with those who had never consulted them. Similar finding had been documented in a previous study in Abakaliki, Ebonyi state, Nigeria. ${ }^{12}$ This corroborates the observation from a study carried out in Kwara State, North-central, Nigeria that $35.4 \%$ of patients referred to traditional bone setters were done by their former patients. ${ }^{40}$ This might be an indication of client's satisfying experience and evidence of good service delivery by the traditional bone setters. ${ }^{12,42}$ Nonetheless, there is need to monitor the activities of traditional bone setters and encourage them to refer patients in order to reduce the rate of complications associated with their management.

Limitations of the study: This was a survey of second-year to sixth-year medical 
students, and hence, its results may not be generalizable to students of other health professions and the general public.

Conclusion: The practice of traditional bone setting is widespread and enjoys much acceptance in the society despite high rates of treatment failures associated with it. Those who have utilized the services of the bone setters were willing to patronize them in future. There is the need to monitor the activities of traditional bone setters to enhance competence and encourage referral. The populace may, also, need to be enlightened on practice of orthopedic surgery.

Acknowledgements: We thank all the study participants for their willingness to take part in the research.

Funding: Authors declare that no external funding was received for this study.

Competing interests: The authors declare that there is no competing interest.

Consent for publication: Not applicable

Availability of data and materials: The dataset used for this study is available and can be obtained from the corresponding author upon request.

Authors' Contributions: ENO conceived and designed the study. ENO, CIA, EII and ATA did the literature searches and supervised data collection, ENO did data analysis, and CIA wrote the initial draft. All authors reviewed and approved the final draft of the manuscript.

\section{REFERENCES}

1. Eshete M. The prevention of traditional bone setter's gangrene-Reply. The Journal of Bone and Joint Surgery. 2005; $\quad 87(1)$ : 1306-1307. doi: 10.1302/0301-620X.16756

2. Agaja SB. Radial club hand, gangrenous as a result of treatment by traditional bone setters: A case report. Nigerian Journal of Orthopaedics and Trauma. 2007; 6 (1): 32-34.

doi: $10.4314 /$ njotra.v6i1.29290

3. Lam TP. Strengths and weaknesses of traditional Chinese medicine and Western medicine in the eyes of some Hong Kong Chinese. Journal of Epidemiology and Community Health. 2001; 55(10): 762-765. doi: 10.1136/jech-2020-215556.

4. Schnell JA. The Merging of Traditional Chinese Medicine and Western Medicine in China: Old Ideas Cross - Culturally Communicated Through New Perspectives. Explorations in Ethnic studies.1989; 12(1): 41-45. doi: $\underline{10.1525 / \text { ees. } 1989.12 .1 .41}$

5. Onuminya JE. The role of the traditional bonesetter in primary fracture care in Nigeria. South African Medical Journal. 2004; 94(8): 652-658.

6. Omololu AB, Ogunlade SO, Gopaldasani VK. The practice of traditional bonesetting: Training algorithm. In: Clinical Orthopaedics and Related Research. Springer New York; 2008; 466(10): 2392-2398. doi: 10.1007/s11999-008-0371-8.

7. Onyemaechi NOC, Lasebikan OA, Elachi IC, Popoola SO, Oluwadiya KS. Patronage of traditional bonesetters in Makurdi, north-central Nigeria. Patient Preference and Adherence. 2015; 9: 275279. doi: $10.2147 /$ PPA.S76877.

8. Thanni LOA. Factors influencing patronage of traditional bone setters. West African Journal of Medicine. 2000;19(3): 220-224.

9. Abang I, Asuquo J, Ngim N, Ikpeme I, Agweye P, Urom S, et al. Reasons for patronage of traditional bone setters. Nigerian Journal of Surgery. 2016; 22(2): 102-106. doi: 10.4103/11176806.188993 
10. Onuminya JE, Onabowale BO, Obekpa $\mathrm{PO}$, Ihezue $\mathrm{CH}$. Traditional bone setter's gangrene. International Orthopaedics. 1999; 23(2): 111-112. doi: $10.1007 / \mathrm{s} 002640050320$.

11. Dada A, Wahab Yinusa SOG. Review of the practice of traditional bone setting in Nigeria. African Health Sciences. 2011; 11(2): 262-265.

12. Ossai EN, Ofojebe OL, Ede DO, Diala LP, Ogbonnaya LU. Willingness to patronize traditional bone setters among patients attending General Out-Patient Department of Federal Teaching Hospital Abakaliki , Nigeria. Austin Orthopedics. 2018; 3(2): 1011.

13. Udosen AM, Otei OO, Onuba O. Role of traditional bone setters in Africa: Experience in Calabar, Nigeria. Annals of African Medicine. 2006; 5(4): 170-173.

14. Odatuwa-Omagbemi DO, Adiki TO, Elachi CI, Bafor A. Complications of traditional bone setters (TBS) treatment of musculoskeletal injuries: Experience in a private setting in Warri, southsouth Nigeria. Pan African Medical Journal. 2018; 30. doi:10.11604/pamj.2018.30.189.15730.

15. Chika A, Onyekwelu J. Traditional bone setters' gangrene: An avoidable catastrophe, 8 years retrospective review in a private orthopedic and trauma center in South-East Nigeria. Nigerian Journal of General Practice. 2016; 14(1): 1-5. doi:10.4103/1118-4647.177496.

16. Nwadiaro HC, Nwadiaro PO, Kidmas AT, Ozoilo KN. Outcome of traditional bone setting in the middle belt of Nigeria. Nigerian Journal of Surgical Research. 2006; 8(1): 44-48.

doi:10.4314/njsr.v8il.54817.

17. Yongu WT, Mue DD, Elachi IC, Kortor JN. Do traditional bone setters have a role in modern fracture management? Journal of Research in Basic and Clinical Sciences. 2019; 1(4): 309-314.

18. Onyemaechi N, Onwuasoigwe O, Nwankwo E. Complications of musculoskeletal injuries treated by traditional bonesetters in a developing country. Indian Journal of Applied Research. 2014; 4: 313-316. doi:10.15373/2249555X/MAR2014/93. doi:10.15373/2249555X/MAR2014/93.
19. Ezeanya-Esiobu C. The case of traditional bone setting and orthopaedic medical curriculum. In: Indigenous knowledge and education in Africa. Frontiers in African Business Research. 2019; pp 81-95. doi: 10.1007/978-981-13-6635-2_6.

20. Eyisi I. Assessing the effect of training of traditional bone setters in Enugu State south east Nigeria. Journal of Health, Medicine and Nursing. 2019; 58:v42-47. doi: $10.7176 /$ jhmn.

21. Onyemaechi NO, Itanyi IU, Ossai PO, Ezeanolue EE. Can traditional bonesetters become trained technicians? Feasibility study among a cohort of Nigerian traditional bonesetters. Human Resources for Health. 2020; 18: 1-8. doi:10.1186/s12960-020-00468-w.

22. Panigrahi TK, Mishra DN, Padhy N. Fracture management by traditional bonesetters: A hospital-based observational study. Journal of Medical Science and Clinical Research. 2017; 5(10): 29177-29182. doi:10.185/jmscr/v5i10.122.

23. OlaOlorum DA, Oladiran IO, Adeniran A. Complications of fracture treatment by traditional bonesetters in southwest Nigeria. Family Practice. 2001; 18(6): 635-637.

doi: $10.1093 /$ fampra/18.6.635

24. Ariës MJH, Joosten $H$, Wegdam HHJ, Van Der Geest S. Fracture treatment by bonesetters in central Ghana: Patients explain their choices and experiences. Tropical Medicine and International Health. 2007; 12(4): 564-574. doi:10.1111/j.1365-3156.2007.01822.x.

25. Omoke N, Ekumankama F. Incidence and pattern of extremity fractures seen in Accident and Emergency Department of a Nigerian teaching hospital. Nigerian Journal of Surgery. 2020; 26(1): 28-34. doi:10.4103/njs.NJS 4219.

26. Omoke NI, Chukwu COO, Madubueze CC, Oyakhiolme OP. Outcome of road traffic injuries received in the emergency room of a teaching hospital, southeast Nigeria. Tropical Doctor. 2012; 42(1): 1822. doi: $10.1258 /$ td.2011.110030.

27. Ebonyi State Goverment | Ministry of Health [Internet]. [cited 2019 Oct 21]. Available from: http://www.ebonyistate. gov.ng/Ministry/Health/ 
28. Agwata JR. knowledge, attitudes and practice of traditional bone setting in iftin division, garissa, Kenya Nairobi.University of Nairobi; 2015. [cited 2020 Jul 26]. Available from: http://erepository.uonbi.ac.ke/bitstrea $\mathrm{m} /$ handle/11295/94521/

29. Olasinde A, Oluwadiya K, Olawoye A, Badru LO, Oginni L, Adegbehingbe $O$. Knowledge, attitude and practice about the traditional bone setters among health workers in Federal Medical Centre, Owo, Nigeria. Sahel Medical Journal. 2004; 6(3): 79-82. doi:10.4314/smj2.v6i3.12842

30. Aderibigbe SA, Agaja SR, Bamidele JO. Determinants of utilization of traditional bone setters in Ilorin, north central Nigeria. Journal of Preventive Medicine and Hygiene. 2013; 54(1): 35-40.

31. Solagberu BA. Long bone fractures treated by traditional bonesetters: A study of patients' behaviour. Tropical Doctor. 2005; 35(2):106. doi: $10.1258 / 0049475054036797$

32. Ogunlusi J, Okem I, Oginni L. Why patients patronize traditional bone setters. Internet Journal of Orthopedic Surgery. 2007; 4(2): 1-7

33. Agarwal A, Agarwal A. The practice and tradition of bonesetting. Clinical Orthopaedics and Related Research. 2010; 23(1): 225. doi:10.1007/s11999008-0371-8.

34. Nwadiaro HC, Ozoilo KN, Nwadiaro PO, Kidmas AT, Oboiren M. Determinants of patronage of traditional bone setters in the middle belt of Nigeria. Nigerian Journal of Medicine. 2008; 17(3): 356359. doi:10.4314/njm.v17i3.37410.

35. Nottidge T, Akpanudo E, Akinbami O. Traditional versus orthodox fracture care in Uyo, Nigeria. Journal of the West African College of Surgeons. 2011; 1(1): 53-67.

36. Omololu B, Ogunlade SO, Alonge TO. The complications seen from the treatment by traditional bonesetters. West African Journal of Medicine. 2002; 21(4): 335-337. doi:10.4314/wajm.v21i4.28014

37. Gölge UH, Kaymaz B, Kömürcü E, Eroğlu M, Göksel F, Nusran G. Consultation of traditional bone setters instead of doctors: Is it a sociocultural and educational or social insurance problem? Tropical Doctor. 2015; 45(2): 91-95. doi:10.1177/0049475514566531

38. Manjunatha V. Patronizing traditional bone setters and its complications - A study in Bangalore. IOSR Journal of Dental and Medical Sciences. 2016; 15(6): 125-130.

39. Ikpeme IA, Udosen AM, Okereke-Okpa I. Patients' perception of traditional bone setting in Calabar. Port Harcourt Medical Journal. 2007; 1(2): doi:10.4314/phmedj.v1i2.38864.

40. Owumi B, Ei, Taiwo PA. The role of significant others in the utilization of traditional orthopaedic services in Kwara State, Nigeria. 2018. [cited 2020 Jul 30]. Available from: http://ir.liberary.ui.edu.ng/handle/ 123 456789/852.

41. Khan I, saeed $M$, Inam $M$, Arif $M$. Traditional bone setters; preference and patronage. Prof Med J. 2015; 22: 11811185.

42. Oluwadiya K, Popoola SO. Knowledge and attitude of healthcare workers towards traditional bone setters in Benue State Nigeria. Nigerian Journal of Orthopaedics and Trauma. 2012; 11(1): $1-7$. 